Abanico Agroforestal. Enero-Diciembre 2020; 2:1-14. http://dx.doi.org/10.37114/abaagrof/2020.10 Artículo Original. Recibido: 17/03/2020. Aceptado: 15/08/2020. Publicado: 10/09/2020. Clave:2020-8.

\title{
Nuevas estrategias de control de mosca blanca, vector de enfermedades virales en chile serrano en el centro y norte de México
}

\author{
New strategies to control of Whitefly: a vector of viral diseases in serrano pepper in \\ central and northern Mexico
}

\section{Luis Barrón-Contreras $^{1 * I D}$, Jaime Mena-Covarrubias ${ }^{2}$ ID Enrique Garza-Urbina $^{3}$}

${ }^{1}$ Campo Experimental San Luis, CIRNE-INIFAP. Soledad de Graciano Sánchez, San Luis Potosí, México. ${ }^{2}$ Campo Experimental Zacatecas, CIRNOC-INIFAP, Zacatecas, México. ${ }^{3}$ Domicilio conocido, Ébano, San Luis Potosí, México. *Autor correspondencia: José Luis Barrón Contreras. Campo Experimental San Luis, CIRNE-INIFAP, Ejido Palma de la Cruz, Soledad de Graciano Sánchez, San Luis Potosí, Km 14.5 Carretera San Luis-Matehuala. CP. 78430. Tel. 01-55-3871-8700 y 01-800-088-2222 extensión 83401. barron.joseluis@inifap.gob.mx,mena.jaime@inifap.gob.mx,enrique_garzaurbina@hotmail.com

\section{Resumen}

El objetivo de este trabajo es identificar nuevas estrategias de control de mosca blanca, vector de enfermedades virales en chile. Con aspersiones dos veces por semana en septiembre y octubre, el rendimiento de chile serrano en un primer corte va de mayor a menor en los tratamientos con: a. Flupyradifurone $150 \mathrm{~g}$ de i.a. / ha $(0.75 \mathrm{~L} / \mathrm{ha})$ septiembre y octubre, b. Flupyradifurone $150 \mathrm{~g}$ de i.a. / ha ( 0.75 L / ha) septiembre / Súper Magro + Caldo Sulfocálcico 10 L de cada uno / ha octubre, c. Súper Magro + Caldo Sulfocálcico $10 \mathrm{~L}$ de cada uno / ha septiembre y octubre y d. Imidacloprid $87.5 \mathrm{~g}$ de i.a. / ha (0.25 $\mathrm{L} / \mathrm{ha}$ ) septiembre y octubre. El Flupyradifurone es una opción eficaz para lograr altos rendimientos y reducir al máximo los daños de mosca blanca y se puede prolongar la vida útil de este producto, evitando la resistencia de los insectos si se alterna con los productos orgánicos. La secuencia Flupyradifurone / mezcla de Súper Magro + Caldo Sulfocálcico mineralizado permite reducir en un $50 \%$ las aplicaciones de insecticida y reduce la presencia de poblaciones de mosca blanca que son capaces de infectar severamente las plantas de chile. A pesar de tener plantas con daño de mosca blanca, cuando se aplican los productos orgánicos, éstas son capaces de lograr altas producciones por hectárea. El Imidacloprid puede ser substituido por Flupyradifurone o bien por la mezcla de Súper Magro + Caldo Sulfocálcico mineralizado. Las 15 aplicaciones realizadas en los meses de septiembre (7) y octubre (8), con Imidacloprid, pueden cambiarse a 15 aplicaciones de orgánicos lo que permitiría una desintoxicación del ambiente productivo de las regiones productoras de chile.

Palabras clave: chile serrano, efectividad, productos químicos y orgánicos, mosca blanca, incidencia de virosis, rendimiento.

\section{Abstract}

The objective of this work is to identify new control strategies for whiteflies, vector of viral diseases in pepper. Spraying the cultivation twice a week in September and October, the yield of chile serrano in a first cut goes from highest to lowest in treatments with: a. Flupyradifurone $150 \mathrm{~g}$ i.a. / ha ( $0.75 \mathrm{~L} / \mathrm{ha})$ in September and October, b. Flupyradifurone 150 g i.a. / ha $(0.75 \mathrm{~L} / \mathrm{ha})$ in September and Super Magro + Sulfocalcium Broth $10 \mathrm{~L}$ of each / ha in October, c. Super Magro + Sulfocalcic Broth $10 \mathrm{~L}$ of each / ha in September and October and d. Imidacloprid $87.5 \mathrm{~g}$ i.a. / ha $(0.25 \mathrm{~L} / \mathrm{ha})$ in September and October. Results shown that Flupyradifurone tratment is an effective option to achieve high yields and minimize whitefly related damage, and the life of of this product can extend, avoiding insect resistance, if its use is alternated with organic 
products. The Flupyradifurone treatment followed by the use of mixture of Super magro + mineralized Sulfocalcic Broth reduces insecticide applications by $50 \%$ and reduces the presence of whitefly populations that are capable of severely infecting chili plants. Despite having plants with whitefly damage, when organic products are applied, they are capable of achieving high yields per hectare. As a conclussion, Imidacloprid can be substituted by Flupyradifurone or by the mixture of Super Magro + mineralized Sulfocalcic Broth. The 15 applications carried out in the months of September (7applications) and October (8 aplications), with Imidacloprid, can be changed for 15 organic applications, which would allow detoxification of the productive environment on the producing regions of pepper.

Keywords: serrano pepper, effectiveness, chemical and organic products, whitefly, incidence of virosis, yield.

\section{INTRODUCCIÓN}

En la Zona Media Potosina los cultivos de chile y jitomate son las especies hortícolas de mayor importancia económica y social (Garza y Rivas, 2003). Las plagas que mayores daños les ocasionan son mosca blanca, (Bemisia tabaci, Gennadius 1889) y (B. argentifolii, Bellows y Perring, 1994), pulgón saltador, (Bactericera cockerelli, Sulc 1909), pulgón verde, (Myzus persicae, Sulzer, 1776), minador de la hoja, (Liriomyza spp., Mik, 1894), barrenillo del chile, (Anthonomus eugenii, Cano), araña roja, (Tetranychus urticae, Koch), gusano del fruto, (Helicoverpa zea, Boddie, 1850) y (Heliothis virescens, Fabricius, 1777), gusano alfiler, (Keiferia lycopersicella, Walsingham, 1897), gusano soldado, (Spodoptera exigua, Hübner, 1808), gusano del cuerno, (Manduca sexta, Linnaeus, 1763), (M. quinquemaculata, Haworth, 1803) y gusano falso medidor (Trichoplusia nii, Hübner, 1800-1803) y (Pseudoplusia includens, Walker, 1858) (Garza, 2002; Garza y Rivas, 2003; Garza et al 2007). En conjunto estas plagas han ocasionado pérdidas de capital a los productores de chile y jitomate (Barrón, 2019).

Del año 2002 a 2007 se desarrolló una estrategia de MIP en los cultivos de chile y jitomate (Garza, 2002, Garza y Rivas, 2003 y Garza et al., 2007). En chile la mosca blanca es trasmisor de geminivirus (Pérez y Rico, 2004), estos tipos de virus ocasionan atrofia en la floración y deformación de hojas y frutos (Rivas, 1994), así como ampollamientos, enanismo, mosaicos, moteados, necrosis, clorosis y acortamiento del ciclo vegetativo (Murphy y Warren, 2003). Para el manejo de mosca blanca y control de virosis la solución fue la aplicación del insecticida Imidacloprid, y a 20 años de uso, para el caso particular de la Zona Media de San Luis Potosí, el problema es el resurgimiento de enfermedades virales en el cultivo de chile, debido a la resistencia desarrollada por la mosca blanca a este insecticida, (Barrón y Garza 2019).

En la actualidad existen productos insecticidas de nueva generación, como el Flupyradifurone, el cual es de baja toxicidad para la mayoría de los insectos benéficos, en especial para polinizadores, y bajo riesgo para la salud humana, con lo cual satisface los requerimientos actuales de los insecticidas modernos necesarios para los programas de manejo integrado de plagas (Nauen et al., 2015); así como productos orgánicos con 
capacidad de controlar las poblaciones de este insecto vector, como lo son los hongos entompatógenos (Abdel-Razek et al., 2017; Stansly y Natwick, 2009) y así reducir el porcentaje de plantas con virosis. El objetivo de este trabajo es identificar nuevas estrategias de control de mosca blanca, vector de enfermedades virales en chile.

\section{Mosca Blanca (Bemisia tabaci) Biotipo B (Hemiptera: Aleyrodidae)}

Importancia Económica. La mosca blanca es una plaga que en los últimos años ha incrementado su incidencia en el cultivo de chile en México. Son varias las causas por las que se deriva su importancia, una de ellas, es el daño directo, ya que al succionar la savia de las plantas las debilita y puede ocasionar la muerte de la planta, sobre todo en sembradíos en los que se presentan altas poblaciones de este insecto; el mayor daño está relacionado con la transmisión de enfermedades de tipo viral (geminivirus), para lo cual es necesario reducir la presencia de poblaciones altas de moscas (Garzón et al., 2002).

Descripción Morfológica. Huevo. Los huevecillos son elípticos y alargados, con el polo superior más agudo que el inferior y llevan en esta parte un pedicelo corto. Son de color verde pálido recién ovipositados y después adquieren una coloración café obscura. Ninfa. Las ninfas son de forma oval, de color amarillo pálido o amarillo verdoso, pasan por cuatro estadios, el primero posee patas y es el único móvil, los demás son ovalados y sin patas; en vista dorsal el cuerpo es más ancho en la parte anterior. Después de que la ninfa ha empezado su alimentación pasa por dos instares ninfales más, los cuales se parecen a "escamas". Al terminar el tercer instar pasa a un período de inactividad y latencia denominada "pupa", durante el cual no se alimenta hasta que llega al estado adulto. Adulto. Las moscas blancas adultas tienen una longitud de $102 \mathrm{~mm}$ y tienen dos pares de alas blancas y un cuerpo amarillento. Su cuerpo está cubierto con un polvo ceroso producido por unas glándulas que se distribuyen por todo el cuerpo. Los adultos se pueden localizar en todas las partes de la planta y pasan la mayor parte del tiempo alimentándose, apareándose y poniendo huevos en el envés de las hojas. Estos insectos se les encuentran en el envés de las hojas y cuando se les disturba vuelan rápidamente (Garza y Rivas, 2003).

Biología, Hábitos y Daños. El daño mayor de esta plaga está relacionado con la transmisión de enfermedades de tipo viral, las cuales afectan el rendimiento y calidad de las cosechas, con daños que varían de 20 a 100\%. Garzón et al., 2002, determinaron la presencia, distribución y hospederos alternos de los Virus Huasteco del Chile (PHV) y del Virus Texano del Chile variante Tamaulipas (TPV-T) en los estados de Guanajuato, San Luis Potosí y Jalisco. El PHV fue el geminivirus con mayor frecuencia en las muestras analizadas con un $70 \%$ de reacciones positivas, por un $19 \%$ del TPV-T, y un $11 \%$ de la mezcla de ambos geminivirus. 


\section{MATERIAL Y MÉTODOS}

El estudio se desarrolló en Rioverde, San Luis Potosí, en una parcela de un productor, establecida el 28 de agosto de 2019 y cultivada con chile serrano variedad Plata, en "segundos cultivos" (de agosto a noviembre de 2019), con acolchado plástico y fertirriego por goteo. El experimento constó de siete tratamientos y cuatro repeticiones (Cuadro 1).

Cuadro 1. Productos químicos y orgánicos, aplicados en chile serrano dos veces por semana para control de mosca blanca, vector de enfermedades virales. Rioverde, San Luis Potosí, 2019.

\section{Productos}

1. Imidacloprid $87.5 \mathrm{~g}$ de i.a. / ha $(0.25 \mathrm{~L} / \mathrm{ha})$

2. Flupyradifurone $150 \mathrm{~g}$ de i.a. / ha $(0.75 \mathrm{~L} / \mathrm{ha})$

3. Súper Magro + Caldo Sulfocálcico $5 \mathrm{~L}$ de cada uno / ha

4. Súper Magro + Caldo Sulfocálcico $10 \mathrm{~L}$ de cada uno / ha

5. Súper Magro + Caldo Sulfocálcico $15 \mathrm{~L}$ de cada uno / ha

6. Súper Magro + Caldo Sulfocálcico $10 \mathrm{~L}$ de cada uno / ha / Flupyradifurone $150 \mathrm{~g}$ de i.a. /ha (0.75 L / ha)

7. Flupyradifurone $150 \mathrm{~g}$ de i.a. /ha $(0.75 \mathrm{~L} / \mathrm{ha})$ / Súper Magro + Caldo Sulfocálcico $10 \mathrm{~L}$ de cada uno / ha

Nota: Tratamientos 1 - 5 la aplicación se realizó de septiembre a octubre.

Tratamientos 6 - 7, se aplicó un mes cada producto (septiembre - octubre).

i.a. $=$ ingrediente activo

La Parcela Experimental (PE) constó de cinco camas de $1.4 \mathrm{~m}$ de ancho y $10 \mathrm{~m}$ de longitud, la parcela útil (PU) constó de tres camas centrales de $8 \mathrm{~m}$ de longitud, y en ellas se contabilizaron las plantas con virosis y rendimiento. Se realizaron un total de 15 aplicaciones, siete en septiembre y ocho en octubre.

Variables evaluadas

1. Fluctuación población de moscas blancas. A los 23, 35, 44 y 51 días después del trasplante (DDT), poco antes de mediodía, se realizaron muestreos con un visor para conocer la fluctuación poblacional. Se contó el número de moscas blancas presentes en cinco plantas por parcela útil, el visor es un cubo de madera sin base para introducir la planta, negra por dentro con vidrio en la parte superior para atraer a la luz los adultos de mosca blanca, (Ávila e Hinojosa, 2000).

2. Número de plantas con presencia de virosis. A los 44 y 57 DDT, se contabilizaron las plantas con presencia de virosis. Se tomó en cuenta como planta con virus aquellas que mostraban los síntomas tales como deformación de hojas, ampollamientos, moteado, clorosis y necrosis, (Barrón et al., 2020). 
3. Número de plantas con daño severo de virosis. A los 44 y 57 DDT, se contabilizaron las plantas con daño severo de virosis. Se tomó en cuenta que las plantas mostraran los síntomas tales como enanismo, atrofia en la floración y deformación de frutos, (Barrón et al., 2020).

4. Rendimiento. La producción de chile serrano obtenido en un primer corte de las tres camas centrales de 1.4 metros de ancho por ocho metros de largo, (Barrón et al., 2020).

Diseño experimental y análisis estadístico

El diseño experimental utilizado fue Bloques al Azar, con siete tratamientos y cuatro repeticiones, los datos se analizaron con el paquete estadístico SAS versión 9.3, con los datos se realizó un análisis de varianza, cuando se encontraron diferencias significativas, se aplicó la prueba de Tukey con un valor de $(\mathrm{P} \leq 0.05)$ para diferenciar tratamientos.

\section{RESULTADOS}

El experimento se inició con una profunda sequía intraestival, con altas temperaturas y bajas precipitaciones (Cuadro 2), posteriormente se tuvo una reducción en la temperatura y un incremento en las precipitaciones. En las cuatro fechas de muestreo siempre fueron más bajas las poblaciones de mosca blanca en los tratamientos 2) Flupyradifurone $150 \mathrm{~g}$ i.a. / ha (0.75 L / ha) septiembre y octubre y 7) Flupyradifurone $150 \mathrm{~g}$ de ingrediente activo/ha (0.75 L / ha) / Súper Magro + Caldo Sulfocálcico 10 L de cada uno/ha (Cuadro 3).

Cuadro 2. Temperaturas máximas, mínimas y promedios mensuales y precipitación en milímetros en los meses de agosto, septiembre y octubre de 2019. Rioverde, San Luis Potosí, 2019.

\begin{tabular}{|c|c|c|c|c|c|c|c|c|c|c|c|}
\hline \multicolumn{12}{|c|}{2019} \\
\hline \multicolumn{3}{|c|}{$\mathrm{T}_{\mathrm{MAXIMA}}{ }^{\circ} \mathrm{C}$} & \multicolumn{3}{|c|}{$\mathrm{T}^{\mathrm{MINIMA}}{ }^{\circ} \mathrm{C}$} & \multicolumn{3}{|c|}{$\mathrm{T}^{\mathrm{MEDIA}}{ }^{\circ} \mathrm{C}$} & \multicolumn{3}{|c|}{ PRECIPITACION mm } \\
\hline AGO & SEP & OCT & AGO & SEP & OCT & AGO & SEP & OCT & AGO & SEP & OCT \\
\hline 37 & 33 & 31 & 20 & 19 & 18 & 28.5 & 26.0 & 24.5 & 52.7 & 76.5 & 125.6 \\
\hline
\end{tabular}

El análisis estadístico del número de adultos de mosca blanca en cinco plantas de chile serrano, promedio de cuatro fechas de muestreo mostró diferencias estadísticas entre los tratamientos $(\mathrm{P}=0.0087)$. El tratamiento con las menores poblaciones de mosca blanca fue Flupyradifurone $150 \mathrm{~g}$ i.a. / ha ( $0.75 \mathrm{~L} / \mathrm{ha})$ septiembre y octubre $(2.4 \mathrm{~B})$ y Flupyradifurone $150 \mathrm{~g}$ de ingrediente activo/ha ( $0.75 \mathrm{~L} / \mathrm{ha}) /$ Súper Magro + Caldo Sulfocálcico $10 \mathrm{~L}$ de cada uno / ha (2.3 B), los cuales son estadísticamente similares entre sí, pero diferentes al resto de los tratamientos (Cuadro 3). Saint-Preux, 2015, trabajando con pulgones Myzus persicae en chile dulce, reporta a Sulfoxaflor y a Flupyradifurone como los productos con menor sobrevivencia de adultos y ninfas después de su aplicación. 
Cuadro 3. Número de adultos de mosca blanca en chile serrano, durante cuatro fechas de muestreo y su promedio, en siete tratamientos con diferentes productos químicos y orgánicos. Rioverde, San Luis Potosí, 2019.

\begin{tabular}{|c|c|c|c|c|c|}
\hline \multirow[t]{2}{*}{ Productos químicos y orgánicos y su dosificación } & \multicolumn{4}{|c|}{$\begin{array}{l}\text { Fechas de muestreo y } \\
\text { moscas blancas en cinco } \\
\text { plantas de chile }\end{array}$} & \multirow[t]{2}{*}{$\begin{array}{l}\text { Promedio de } \\
\text { moscas } \\
\text { blancas }\end{array}$} \\
\hline & $\begin{array}{c}20 \\
\text { sept. }\end{array}$ & $\begin{array}{c}02 \\
\text { oct. }\end{array}$ & $\begin{array}{c}11 \\
\text { oct. }\end{array}$ & $\begin{array}{c}18 \\
\text { oct. }\end{array}$ & \\
\hline 1. Imidacloprid $87.5 \mathrm{~g}$ de i.a. / ha (0.25 L / ha) & 3.3 & 7.8 & 3.8 & 3.3 & $4.5 \mathrm{AB}$ \\
\hline 2. Flupyradifurone $150 \mathrm{~g}$ de i.a. / ha $(0.75 \mathrm{~L} / \mathrm{ha})$ & 4.3 & 2.8 & 1.3 & 1.5 & $2.4 \mathrm{~B}$ \\
\hline $\begin{array}{l}\text { 3. Súper Magro + Caldo Sulfocálcico } 5 \text { L de cada } \\
\text { uno / ha }\end{array}$ & 7.5 & 10.0 & 4.8 & 3.0 & $6.3 \mathrm{~A}$ \\
\hline $\begin{array}{l}\text { 4. Súper Magro + Caldo Sulfocálcico } 10 \mathrm{~L} \text { de cada } \\
\text { uno / ha }\end{array}$ & 6.0 & 7.0 & 3.0 & 4.5 & $5.1 \mathrm{AB}$ \\
\hline $\begin{array}{l}\text { 5. Súper Magro + Caldo Sulfocálcico } 15 \mathrm{~L} \text { de cada } \\
\text { uno / ha }\end{array}$ & 5.5 & 6.0 & 4.5 & 4.0 & $5.0 \mathrm{AB}$ \\
\hline $\begin{array}{l}\text { 6. Súper Magro + Caldo Sulfocálcico } 10 \mathrm{~L} \text { de cada } \\
\text { uno / ha / Flupyradifurone } 150 \mathrm{~g} \text { de i.a. /ha (0.75 } \\
\mathrm{L} \text { / ha) }\end{array}$ & 5.8 & 8.3 & 1.5 & 2.8 & 4.6 AB \\
\hline $\begin{array}{l}\text { 7. Flupyradifurone } 150 \mathrm{~g} \text { de i.a. /ha }(0.75 \mathrm{~L} / \mathrm{ha}) \text { / } \\
\text { Súper Magro + Caldo Sulfocálcico } 10 \mathrm{~L} \text { de cada } \\
\text { uno / ha }\end{array}$ & 2.0 & 2.3 & 1.8 & 3.0 & $2.3 \mathrm{~B}$ \\
\hline \multicolumn{6}{|c|}{$\begin{array}{l}\text { Medias con la misma literal no son significativamente diferentes al } 0.05 \% \text { de probabilidad. } \\
\text { * (Promedio de } 4 \text { fechas de muestreo: } 23,35,44 \text { y } 51 \text { DDT). }\end{array}$} \\
\hline
\end{tabular}

\section{Plantas con síntomas de virosis}

A los 44 y 57 DDT la variable \% de plantas de chile con síntomas de virosis, reportó diferencias estadísticas entre los tratamientos $(\mathrm{P}<0.0001$ y $\mathrm{P}=0.0144$, respectivamente; Cuadro 4).

44 DDT del cultivo de chile, con 10 aplicaciones de los productos evaluados, el porcentaje de plantas con síntomas de virosis tuvo un rango de 3.7 a $23.4 \%$ (Cuadro 4). Los tratamientos menos afectados por virus fueron donde se aplicó Flupyradifurone $150 \mathrm{~g}$ i.a. / ha $(0.75 \mathrm{~L}$ / ha) septiembre y octubre $(3.7 \% \mathrm{C})$, Flupyradifurone $150 \mathrm{~g}$ de ingrediente activo/ha (0.75 L / ha) / Súper Magro + Caldo Sulfocálcico 10 L de cada uno/ha (4.0\% C) y Súper Magro + Caldo Sulfocálcico $10 \mathrm{~L}$ de cada uno/ha / Flupyradifurone $150 \mathrm{~g}$ de ingrediente activo/ha $(0.75 \mathrm{~L} / \mathrm{ha})(6.8 \% \mathrm{C})$, estadísticamente iguales y diferentes al resto de los tratamientos $(P \leq 0.05)$. 
A 57 días posteriores al trasplante del cultivo de chile, habiendo transcurrido 13 días después del primer muestreo, y completando ya 13 aplicaciones, el porcentaje de plantas con síntomas de virosis se incrementó y tuvo una variación de 8.5 a 45.7 \% (Cuadro 4), siendo menos afectados el tratamiento donde se aplicó Flupyradifurone $150 \mathrm{~g}$ i.a. / ha $(0.75 \mathrm{~L} / \mathrm{ha})$ septiembre y octubre $(8.5 \% \mathrm{~B})$ y Flupyradifurone $150 \mathrm{~g}$ de ingrediente activo/ha (0.75 L / ha) / Súper Magro + Caldo Sulfocálcico 10 L de cada uno/ha (15.9\% $\mathrm{C})$, estadísticamente iguales y diferentes al resto de los tratamientos $(P \leq 0.05)$.

Cuadro 4. Porcentaje de plantas de chile con síntomas de virosis 44 y 57 días post trasplante, en tratamientos con diferentes productos químicos y orgánicos. Rioverde, San Luis Potosí, 2019.

\begin{tabular}{|c|c|c|c|}
\hline & \multirow[t]{2}{*}{ Productos químicos y orgánicos y su dosificación } & \multicolumn{2}{|c|}{$\begin{array}{l}\text { \% de plantas de chile con } \\
\text { síntomas de virosis }\end{array}$} \\
\hline & & (44 DDT) & (57 DDT) \\
\hline 1. & Imidacloprid $87.5 \mathrm{~g}$ de i.a. / ha $(0.25 \mathrm{~L} / \mathrm{ha})$ & $12.8 \mathrm{BC}$ & $28.6 \mathrm{AB}$ \\
\hline 2. & Flupyradifurone $150 \mathrm{~g}$ de i.a. / ha (0.75 L / ha) & $3.7 \mathrm{C}$ & $8.5 \mathrm{~B}$ \\
\hline 3. & Súper Magro + Caldo Sulfocálcico $5 \mathrm{~L}$ de cada uno / ha & $11.3 \mathrm{BC}$ & $29.1 \mathrm{AB}$ \\
\hline 4. & Súper Magro + Caldo Sulfocálcico $10 \mathrm{~L}$ de cada uno / ha & $23.4 \mathrm{~A}$ & $45.7 \mathrm{~A}$ \\
\hline 5. & Súper Magro + Caldo Sulfocálcico 15 L de cada uno / ha & $21.0 \mathrm{AB}$ & $33.9 \mathrm{AB}$ \\
\hline 6. & $\begin{array}{l}\text { Súper Magro + Caldo Sulfocálcico } 10 \mathrm{~L} \text { de cada uno / ha / } \\
\text { Flupyradifurone } 150 \mathrm{~g} \text { de i.a. /ha }(0.75 \mathrm{~L} / \mathrm{ha})\end{array}$ & $6.8 \mathrm{C}$ & $25.8 \mathrm{AB}$ \\
\hline 7. & $\begin{array}{l}\text { Flupyradifurone } 150 \mathrm{~g} \text { de i.a. /ha ( } 0.75 \mathrm{~L} / \mathrm{ha}) \text { / Súper Magro } \\
+ \text { Caldo Sulfocálcico } 10 \mathrm{~L} \text { de cada uno / ha }\end{array}$ & $4.0 \mathrm{C}$ & $15.9 \mathrm{~B}$ \\
\hline
\end{tabular}
Medias con la misma literal no son significativamente diferentes al $0.05 \%$ de probabilidad.

Nota: Tratamientos 1 - 5 la aplicación se realizó de septiembre a octubre.

Tratamientos 6 - 7, se aplicó un mes cada producto (septiembre - octubre).

i.a. $=$ ingrediente activo

\section{Plantas con daño severo de virosis}

A los 44 y 57 DDT la variable \% de plantas de chile con daño severo de virosis, reportó diferencias estadísticas entre los tratamientos $(P=0.0070$ y $P=0.0167$, respectivamente; Cuadro 5).

A los 44 DDT del cultivo de chile y 10 aplicaciones de los productos evaluados, el porcentaje de plantas con daño severo de virosis cambió de 0.2 a $2.9 \%$ (Cuadro 5). Los tratamientos menos afectados fueron donde se aplicó Flupyradifurone $150 \mathrm{~g}$ i.a. / ha $(0.75$ $\mathrm{L} / \mathrm{ha})$ septiembre y octubre $(0.2 \% \mathrm{~B})$ y Flupyradifurone $150 \mathrm{~g}$ de ingrediente activo/ha (0.75 L / ha) / Súper Magro + Caldo Sulfocálcico $10 \mathrm{~L}$ de cada uno/ha (0.2\% B), estadísticamente iguales y diferentes al resto de los tratamientos $(p \leq 0.05)$. 
A los 57 DDT del cultivo de chile, habiendo transcurrido 13 días después del primer muestreo y completando ya 13 aplicaciones, el porcentaje de plantas con daño severo de virosis varío de 0.7 a $9.6 \%$ (Cuadro 5), siendo menos afectados el tratamiento con Flupyradifurone $150 \mathrm{~g}$ i.a. / ha $(0.75 \mathrm{~L} / \mathrm{ha})$ septiembre y octubre $(0.7 \% \mathrm{~B})$ y Flupyradifurone $150 \mathrm{~g}$ de ingrediente activo/ha $(0.75 \mathrm{~L} / \mathrm{ha}) /$ Súper Magro + Caldo Sulfocálcico $10 \mathrm{~L}$ de cada uno/ha $(1.0 \% \mathrm{~B})$, estadísticamente iguales y diferentes al resto de los tratamientos $(P \leq 0.05)$.

Cuadro 5. Porcentaje de plantas de chile con daño severo de virosis 44 y 57 días post trasplante, en tratamientos con diferentes productos químicos y orgánicos. Rioverde, San Luis Potosí, 2019.

Productos químicos y orgánicos y su dosificación

$\%$ de plantas de chile con daño

severo de virosis

\begin{tabular}{|c|c|c|c|}
\hline & & \\
\hline & & (44 DDT) & (57 DDT) \\
\hline & Imidacloprid $87.5 \mathrm{~g}$ de i.a. / ha (0.25 L / ha) & $2.9 \mathrm{~A}$ & $5.7 \mathrm{AB}$ \\
\hline 2. & Flupyradifurone $150 \mathrm{~g}$ de i.a. / ha (0.75 L / ha) & $0.2 \mathrm{~B}$ & $0.7 \mathrm{~B}$ \\
\hline 3. & Súper Magro + Caldo Sulfocálcico 5 L de cada uno / ha & $2.8 \mathrm{~A}$ & $4.2 \mathrm{AB}$ \\
\hline 4. & Súper Magro + Caldo Sulfocálcico 10 L de cada uno / ha & $1.8 \mathrm{AB}$ & $6.0 \mathrm{AB}$ \\
\hline 5. & Súper Magro + Caldo Sulfocálcico $15 \mathrm{~L}$ de cada uno / ha & $1.8 \mathrm{AB}$ & $9.6 \mathrm{~A}$ \\
\hline 6. & $\begin{array}{l}\text { Súper Magro + Caldo Sulfocálcico } 10 \mathrm{~L} \text { de cada uno / ha / } \\
\text { Flupyradifurone } 150 \mathrm{~g} \text { de i.a. /ha }(0.75 \mathrm{~L} / \mathrm{ha})\end{array}$ & $1.0 \mathrm{AB}$ & $3.1 \mathrm{AB}$ \\
\hline 7. & $\begin{array}{l}\text { Flupyradifurone } 150 \mathrm{~g} \text { de i.a. /ha ( } 0.75 \mathrm{~L} \text { / ha) / Súper Magro + } \\
\text { Caldo Sulfocálcico } 10 \mathrm{~L} \text { de cada uno / ha }\end{array}$ & $0.2 \mathrm{~B}$ & $1.0 \mathrm{~B}$ \\
\hline
\end{tabular}

Medias con la misma literal no son significativamente diferentes al $0.05 \%$ de probabilidad.

Nota: Tratamientos 1 - 5 la aplicación se realizó de septiembre a octubre.

Tratamientos 6 - 7, se aplicó un mes cada producto (septiembre - octubre).

i.a. $=$ ingrediente activo

Rodríguez y Terán (2017) con base a estudios de efectividad de agroquímicos en sorgo, recomiendan el uso del insecticida Flupyradifurone para el combate de insectos chupadores como el pulgón amarillo del sorgo (Melanaphis saccharih) en áreas agrícolas donde se ha utilizado masivamente el Imidacloprid, incrementando así las opciones para el control químico, lo que reduce el riesgo de que la plaga desarrolle resistencia al utilizar productos de diferente grupo químico. Por su parte Rodríguez et al. (2012), en ensayos de laboratorio con moscas blancas colectadas en campo, encontraron resistencia alta a Metamidofos y algunos casos de resistencia intermedia a Cipermetrina, Imidacloprid y Thioxyclam hidrógeno oxalato en adultos de mosca blanca; así mismo en localidades con exagerado uso de insecticidas; encontraron niveles de resistencia intermedia a Imidacloprid, Buprofezin y Diafentiuron.

El Cuadro 6 muestra que a los 87 días posteriores al trasplante y después de 15 aplicaciones, se observaron diferencias estadísticas entre los tratamientos ( $P=0.0172)$; el 
tratamiento donde se aplicó Flupyradifurone $150 \mathrm{~g}$ i.a. / ha $(0.75 \mathrm{~L} / \mathrm{ha})$ septiembre y octubre tuvo una producción de 18.4 toneladas de chile serrano por hectárea $(\mathrm{A})$ estadísticamente diferente al resto de los tratamientos, en el resto $(1,3,4,6$ y 7$)$ no hubo diferencias estadísticas significativas entre ellos $(P \geq 0.05)$, el tratamiento con la aplicación de Súper Magro + Caldo Sulfocálcico $15 \mathrm{~L}$ de cada uno / ha septiembre y octubre 5) también fue diferente, pero con la menor producción de chile por hectárea (10.9 B).

Cuadro 6. Toneladas de chile por hectárea en el primer corte a los 87 días post trasplante, en tratamientos con diferentes productos químicos y orgánicos. Rioverde, San Luis Potosí, 2019.

Productos químicos y orgánicos y su dosificación, asperjados dos veces por semana en plantas de chile serrano establecido el 28 de agosto de 2019

1. Imidacloprid $87.5 \mathrm{~g}$ de i.a. / ha $(0.25 \mathrm{~L} / \mathrm{ha})$

2. Flupyradifurone $150 \mathrm{~g}$ de i.a. / ha $(0.75 \mathrm{~L} / \mathrm{ha})$

3. Súper Magro + Caldo Sulfocálcico $5 \mathrm{~L}$ de cada uno / ha

4. Súper Magro + Caldo Sulfocálcico $10 \mathrm{~L}$ de cada uno / ha

5. Súper Magro + Caldo Sulfocálcico $15 \mathrm{~L}$ de cada uno / ha

6. Súper Magro + Caldo Sulfocálcico $10 \mathrm{~L}$ de cada uno / ha / Flupyradifurone $150 \mathrm{~g}$ de i.a. /ha $(0.75 \mathrm{~L} / \mathrm{ha})$

7. Flupyradifurone $150 \mathrm{~g}$ de i.a. /ha $(0.75 \mathrm{~L} / \mathrm{ha}) /$ Súper Magro + Caldo Sulfocálcico $10 \mathrm{~L}$ de cada uno / ha
Toneladas de chile por hectárea en un solo

corte

14.3 $\mathrm{AB}$

$18.4 \mathrm{~A}$

$14.3 \mathrm{AB}$

$14.5 \mathrm{AB}$

$10.9 \mathrm{~B}$

$16.1 \mathrm{AB}$

$15.2 \mathrm{AB}$

Medias con la misma literal no son significativamente diferentes al $0.05 \%$ de probabilidad.

Nota: Tratamientos 1 - 5 la aplicación se realizó de septiembre a octubre.

Tratamientos 6 - 7, se aplicó un mes cada producto (septiembre - octubre).

i.a. $=$ ingrediente activo

\section{DISCUSIÓN}

El tratamiento de Flupyradifurone $150 \mathrm{~g}$ i.a. / ha $(0.75 \mathrm{~L} / \mathrm{ha})$ septiembre y octubre es efectivo para reducir la presencia de virosis en plantas de chile, así como las poblaciones de mosca blanca. La ficha técnica de este producto señala que su acción es translaminar y sistémica vía xilema (Nauen et al., 2015). El ingrediente activo se deposita en las hojas y los tallos con aplicación por pulverización. Después de la absorción en la planta, se traspasa de forma acrópeta (sentido ascendente) en el xilema, siguiendo el flujo de la transpiración, y se distribuye translaminarmente a las células adyacentes de la planta (Nauen et al., 2015). Debido a este movimiento translaminar, tiene éxito contra los insectos que se alimentan en la parte de abajo de la hoja, incluso cuando solamente se aplica a la parte superior de la hoja. El efecto duradero del producto da como resultado un trastorno del sistema nervioso del insecto, al afectar los receptores nicotínicos de la acetil colina (Nauen et al., 2015), causando su colapso. El Flupyradifurone es una opción eficaz para lograr altos rendimientos y reducir al máximo los daños de insectos 
chupadores, Rodríguez y Terán (2017) y se puede prolongar la vida útil de este producto, evitando la resistencia de los insectos si se alterna con los productos orgánicos.

Bajo la propuesta de recurrir a estrategias que minimicen el impacto adverso de las aspersiones en los ecosistemas agrícolas surge como alternativa de control para mosca blanca el tratamiento Flupyradifurone $150 \mathrm{~g}$ i.a. / ha $(0.75 \mathrm{~L} / \mathrm{ha})$ septiembre / Súper Magro + Caldo Sulfocálcico mineralizado $10 \mathrm{~L}$ de cada uno / ha octubre. Estos productos intercalados mantienen una menor población de adultos de mosca blanca y un bajo porcentaje de plantas con virus. La secuencia Flupyradifurone / mezcla de Súper Magro + Caldo Sulfocálcico mineralizado permite reducir en un 50\% las aplicaciones de insecticida y reduce la presencia de poblaciones de mosca blanca que son capaces de infectar severamente las plantas de chile, lo cual es otra opción de manejo que permite reducir la cantidad del insecticida aplicado, como se reportó para el manejo de $B$. tabaci en algodón al combinar los insecticidas profenofos, imidacloprid o cyhalotrina con el ácido acetil salicílico (El et al., 2019). Con el tratamiento Súper Magro + Caldo Sulfocálcico mineralizado $10 \mathrm{~L}$ de cada uno / ha septiembre y octubre, se logra una producción aceptable de chile por hectárea.

La mezcla de Súper Magro + Caldo Sulfocálcico mineralizado es sinérgica para el cultivo por las siguientes razones: Súper Magro es un fertilizante orgánico (fermentado de manera anaeróbica), con mucha energía equilibrada y en armonía mineral, nutre, recupera y reactiva la vida del suelo, incrementa la nutrición de las plantas y estimula la protección de los cultivos contra el ataque de plagas, activa las defensas de las plantas a través de los ácidos orgánicos, hormonas de crecimiento, antibióticos, vitaminas, minerales, enzimas, coenzimas, carbohidratos, aminoácidos y azúcares. El Caldo Sulfocálcico, mineralizado, es preparado a base de azufre $+\mathrm{cal}$, enriquecido con minerales. Al hervir el azufre y la cal reacciona formando Polisulfuro de calcio, el cual enriquece y aumenta la solubilidad de elementos retenidos en el suelo y como insecticida controla a la mosca blanca matándola por asfixia y por su acción abrasiva; además se menciona que tiene un efecto soldador de la cadena de aminoácidos libres y azúcares (Restrepo, 1996). La mezcla de los dos productos anteriores va dirigida a alterar uno 0 más de los participantes primarios en el proceso de transmisión de virus por mosca blanca (el insecto vector, la planta hospedera fuente de los virus y/o el cultivo) (Horowitz et al., 2011).

La activación de las defensas de las plantas contra el ataque de las plagas, utilizando el Súper Magro y Caldo Sulfocálcico, mineralizado en el cultivo, a pesar de tener daño por mosca blanca, las plantas son capaces de lograr altas producciones por hectárea, situación que coincide con lo documentado por Jarquín et al. (2013), además de que es uno de los retos actuales en el manejo de mosca blanca: el de mantener la productividad del cultivo y minimizar el impacto sobre el ambiente y la biodiversidad (Stansly y Natwick, 
2009). De acuerdo a Restrepo, (2007), las plantas con daño de insectos, cuando se aplican los productos orgánicos, son capaces de lograr altas producciones por hectárea.

Cabe señalar que, en este trabajo, el insecticida Imidacloprid de uso regional siempre presentó un alto porcentaje de plantas con virosis a pesar del alto número de aplicaciones.

Las aplicaciones a realizar en los meses de septiembre y octubre con Imidacloprid, pueden cambiarse por aplicaciones de productos orgánicos lo que permitirá una desintoxicación del ambiente productivo de las regiones productoras de chile.

Esta estrategia puede ser aplicable en todas las regiones chileras que tengan problemas de mosca blanca. Es necesario atender las recomendaciones que para cada insecticida recomienda su etiqueta, es muy común el realizar dos o tres aplicaciones durante el periodo de control; mas aplicaciones puede ocasionar problemas de resistencia, sin embargo, esto puede ser variable para cada región de acuerdo al historial de uso de un mismo insecticida.

\section{CONCLUSIONES}

- Con aspersiones dos veces por semana en septiembre y octubre, el rendimiento de chile serrano en un primer corte va de mayor a menor en los tratamientos con: a. Flupyradifurone $150 \mathrm{~g}$ de i.a. / ha $(0.75 \mathrm{~L} / \mathrm{ha})$ septiembre y octubre

b. Flupyradifurone $150 \mathrm{~g}$ de i.a. / ha $(0.75 \mathrm{~L} / \mathrm{ha})$ septiembre / Súper Magro + Caldo Sulfocálcico $10 \mathrm{~L}$ de cada uno / ha octubre

c. Súper Magro + Caldo Sulfocálcico $10 \mathrm{~L}$ de cada uno / ha septiembre y octubre d. Imidacloprid $87.5 \mathrm{~g}$ de i.a. / ha $(0.25 \mathrm{~L} / \mathrm{ha})$ septiembre y octubre

- El Flupyradifurone es una opción eficaz para lograr altos rendimientos y reducir al máximo los daños de mosca blanca y se puede prolongar la vida útil de este producto, evitando la resistencia de los insectos si se alterna con los productos orgánicos.

- La secuencia Flupyradifurone / mezcla de Súper Magro + Caldo Sulfocálcico mineralizado permite reducir en un $50 \%$ las aplicaciones de insecticida y reduce la presencia de poblaciones de mosca blanca que son capaces de infectar severamente las plantas de chile.

- A pesar de tener plantas con daño de mosca blanca, cuando se aplican los productos orgánicos, éstas son capaces de lograr altas producciones por hectárea.

- El Imidacloprid puede ser substituido por Flupyradifurone o bien por la mezcla de Súper Magro + Caldo Sulfocálcico mineralizado. 
- Las 15 aplicaciones realizadas en los meses de septiembre (7) y octubre (8), con Imidacloprid, pueden cambiarse a 15 aplicaciones de orgánicos lo que permitiría una desintoxicación del ambiente productivo de las regiones productoras de chile.

\section{LITERATURA CITADA}

ABDEL-RAZEK AS, El-Ghany NMA, Djelouah K, Moussa A. 2017. An evaluation of some eco-friendly biopesticides against Bemisia tabaci on two greenhouse tomato varieties in Egypt. Journal of Plant Protection Research 57(1): 9-17.

https://doi.org/10.1515/jppr-2017-0002

ÁVILA VJ, Hinojosa RI. 2000. Manejo integrado de mosca blanca. Folleto Técnico Núm. 16. INIFAP-CIRNE. Campo Experimental Sur de Tamaulipas. México. Pp. 24. http://inifapcirne.gob.mx/Biblioteca/consultasistprodnueva.php?sispro=58

BARRÓN CJ, Garza UE. 2019. Control de mosca blanca, vector de enfermedades virales en chile serrano en San Luis Potosí, México. Memorias del III Congreso Mundial de Agricultura Tropical. Tampico, Tamaulipas, México.

http://www.agriculturatropical.org/?page_id=645

BARRÓN CJL. 2019. Alternativas de control de mosca blanca Bemisia tabaci Biotipo B, vector de enfermedades virales en chile Capsicum annuum en San Luis Potosí, México, Pp. 25-26, en: Tecnologías Generadas, Validadas, Transferidas o Adoptadas en los Estados de Tamaulipas, San Luis Potosí, Coahuila y Nuevo León en el año de 2018. CIRNE-INIFAP. México. Folleto Técnico No. MX-0-310301-52-03-13-09-76. ISBN: 978607-37-1153-1.

http://inifapcirne.gob.mx//FTP/Dirlnvestigacion/FOLLETO TECNOLOGIAS 2018.pdf

BARRÓN CJL, Mena CJ, Garza UE. 2020. Estrategias de control de mosca blanca, Bemisia spp /Hemiptera: Aleyrodidae) vector de enfermedades virales en chile serrano, Capsicum annuum L. Memorias del IV Congreso Internacional Abanico Veterinario, Agroforestal, Pesquero y Acuícola 2020. Nayarit, México.

https://abanicoacademico.mx/revistasabanico/index.php/CIAVAPA/issue/view/51

EL-HAKEEM El-Dmerdash El-Sherbeni, Mohamed Sengab Khaleid, Sabry Abd EI All AbdAllah, Ola Saber Mohammed Ali. 2019. Effect of some insecticides alone and in combination with salicylic acid against aphid, Aphis gossypii, and whitefly Bemisia tabaci on the cotton field. Bulletin of the National Research Centre. 43(1): 43-57.

https://doi.org/10.1186/s42269-019-0103-0

GARZA UE. 2002. Manejo integrado de las plagas del chile en la Planicie Huasteca. Folleto Técnico Núm. 10. Campo Experimental Ébano, CIRNE-INIFAP. México. Pp. 47. http://inifapcirne.gob.mx/Biblioteca/consultasistprodnueva.php?sispro=58 
GARZA UE, Rivas MA. 2003. Manejo integrado de las plagas del chile y jitomate en la Zona Media de San Luis Potosí. Folleto para Productores Núm. 5. Campo Experimental Ébano, CIRNE-INIFAP. México. Pp. 48.

http://inifapcirne.gob.mx/Biblioteca/consultasistprodnueva.php?sispro=58

GARZA UE, Rivas MA, Moreno Ch JG. 2007. Manejo integrado de las plagas del chile y jitomate en el Altiplano de San Luis Potosí. Folleto para Productores Núm. 9. Campo Experimental Sur de Tamaulipas. CIRNE-INIFAP. México. Pp. 45.

http://inifapcirne.gob.mx/Biblioteca/consultasistprodnueva.php?sispro=58

GARZÓN TJA, Acosta GG, Torres PI, González ChM, Rivera BRF, Maya HV, Guevara GRG. 2002. Presencia de los Geminivirus, Huasteco del Chile (PHV), Texano del Chile variante Tamaulipas (TPV-T), y Chino del Tomate (VCdT), en los estados de Guanajuato, Jalisco y San Luis Potosí, México. Revista Mexicana de Fitopatología. 20:45-52.

https://www.redalyc.org/articulo.oa?id=61220108\&idp $=1 \& \mathrm{cid}=2854043$

HOROWITZ AR, Antignus Y, Gerling D. 2011. Management of Bemisia tabaci whiteflies. In The Whitefly, Bemisia tabaci (Homoptera: Aleyrodidae) Interaction with GeminivirusInfected Host Plants. Springer, Dordrecht. Pp. 293-322.

https://doi.org/10.1007/978-94-007-1524-0_11

JARQUIN GR, Schwentesius R, Escalona AMA, Ramírez THM, Domínguez GN. 2013. Guía para la compresión de lineamientos técnicos de operación orgánica. Facultad de Agronomía y Veterinaria de la UASLP. México. Pp. 88.

MURPHY JF, Warren CE. 2003. Diseases caused by viruses. Compendium of pepper diseases. APS PRESS. Pp. 23-24. USA. ISBN: 9780890543009

NAUEN R, Jeschke $P$, Velten R, Beck ME, Ebbinghaus-Kintscher U, Thielert Wolfgang Thielert, W, Wölfel K, Haas M, Kunz K, Raupach G. 2015. Flupyradifurone: a brief profile of a new butenolide insecticide. Pest management science. 71(6): 850-862.

https://doi.org/10.1002/ps.3932

PÉREZ ML, Rico JE. 2004. Virus fitopatógenos en cultivos hortícolas de importancia económica en el estado de Guanajuato. Primera edición. Universidad de Guanajuato. México. Pp. 143. ISSN 0185-3309

http://201.144.45.148/cgi-bin/koha/opac-detail.pl?biblionumber=26847

RESTREPO RJ. 2007. Manual práctico, EL A, B, C de la agricultura orgánica y harina de rocas. Nicaragua.

http://simas.org.ni/media/1311796944_El\%20ABC\%20de\%20la\%20agricultura-

presentacion.pdf 
RESTREPO RJ. 1996. Abonos orgánicos fermentados, Experiencias de agricultores en Centroamérica y Brasil. Inédito.

http://www.motril.es/fileadmin/areas/medioambiente/ae/ABONOSORGANICOSFERMEN TADOS.pdf

RIVAS PG. 1994. Geminivirus: Virus transmitidos por las moscas blancas. Hoja Técnica. Boletín Informativo MIP N³3. Costa Rica.

https://doi.org/10.13140/RG.2.2.28160.99849

RODRÍGUEZ TIV, Bueno MJM, Cardona MC, Morales MH. 2012. Biotipo B de Bemisia tabaci (Hemiptera: Aleyrodidae): plaga de pimentón en el Valle del Cauca, Colombia. Revista Colombiana de Entomología. 38 (1): 14-22 (2012).

http://www.scielo.org.co/pdf/rcen/v38n1/v38n1a03.pdf

RODRÍGUEZ del Bosque LA, Terán Vargas AP. 2017. Uso del insecticida Flupyradifurone para el combate del pulgón amarillo del sorgo. Pp. 37-38, en: Tecnologías Generadas, Validadas, Transferidas o Adoptadas en los Estados de Tamaulipas, San Luis Potosí, Coahuila y Nuevo León en el año 2016. CIRNE-INIFAP. México. Folleto Técnico No. MX0-310301-52-03-13-09-68. ISBN: 978-607-37-0861-6.

http://inifapcirne.gob.mx//FTP/Dirlnvestigacion/FOLLETO TECNICO TECNOLOGIAS CIRNE 2016.pdf

SAINT-PREUX C. 2015. Comparación de la eficacia del insecticida Sulfoxaflor con Flupyradifurone, Spirotetramate e Imidacloprid para el control de Myzus persicae en chile dulce (Capsicum annuum). Tesis de Maestría. Escuela Agrícola Panamericana, Zamorano. Honduras.

https://bdigital.zamorano.edu/bitstream/11036/4626/1/CPA-2015-079.pdf

SAS/STAT. 2010. SAS system for windows. Versión 9.3. SAS Institute Inc. Campus Drive, Cary, North Carolina 27513.

STANSLY PA, Natwick ET. 2009. Integrated systems for managing Bemisia tabaci in protected and open field agriculture. In: Stansly P, Naranjo S. (eds) Bemisia: bionomics and management of a global pest. Springer, Dordrecht. Pp. 467-497. https://doi.org/10.1007/978-90-481-2460-2_17 